\title{
O Conceito de pensamento em Empirismo e Filosofia da Mente de Wilfrid Sellars
}

\author{
TAIGON MARQUES GONÇALVES *
}

\begin{abstract}
RESUMO No presente aretigo pretendo apresentar e avaliar o modo como Wilfrid Sellars entende o conceito de pensamento em seu ensaio Empirismo e Filosofia da Mente (abreviado por EFM). Começaremos fazendo uma breve caracterização das duas teorias da mente que disputavam a hegemonia no cenário filosófico da época. Falaremos também dos problemas que assolavam essas teorias e de como eles motivaram Sellars a desenvolver sua própria posição. Em seguida, apresentaremos o experimento mental que Sellars desenvolve entre as partes XII e XVI do seu ensaio - o chamado "mito ryliano" - para avançar as linhas gerais de sua própria filosofia da mente. Analisaremos em detalhes as “etapas” do experimento mental, cujo objetivo mais geral é mostrar que os conceitos psicológicos devem ser entendidos como derivados da linguagem pública e intersubjetiva. Mais especificamente, no que tange ao tema do trabalho, a tese a ser defendida com o experimento é a de que o entendimento do conceito de pensamento pressupõe o entendimento de conceitos metalinguísticos. Por fim, faremos algumas rápidas observações no sentido de como o "mito ryliano" pode ser avaliado, apontando possíveis dificuldades e caminhos para superá-las.
\end{abstract}

PALAVRAS-ChaVe Sellars; pensamento; linguagem psicológica; "mito ryliano".

* Doutorando em Filosofia | Pontifícia Universidade Católica do Rio de Janeiro Bolsista CNPq 


\section{CARTESIANISMO X BEHAVIORISMO LÓGICO}

Da era moderna até meados do séc. XX a filosofia da mente foi dominada por aquilo que poderíamos chamar - de um modo genérico - de cartesianismo. Resumidamente, a tradição cartesiana era caracterizada por três teses principais: (i) estados mentais envolvem um sujeito se relacionando de uma determinada forma com um determinado objeto; (ii) a natureza dos objetos mentais é completamente diferente da natureza dos objetos físicos; (iii) o conhecimento que o sujeito tem dos seus próprios objetos mentais é imediato, direto - consequentemente, os estados mentais do próprio sujeito são transparentes e ele.

A imensa variedade dos nossos estados mentais era explicada tanto em função da variedade dos objetos com os quais o sujeito se relaciona como em função da própria forma dessa relação. Além disso, a assimetria ontológica entre o físico e o mental parece ao mesmo tempo apoiar e ser apoiada pela assimetria epistemológica entre o físico e o mental. Pelo próprio fato de serem objetos mentais, eles estão em "contato direto" com o sujeito, que por sua vez os conhece melhor do que os objetos físicos, em relação aos quais o sujeito tem no máximo um acesso falível.

Embora a concepção cartesiana de mente fosse bastante atrativa pelo seu caráter intuitivo, ela sempre deu espaço para questionamentos céticos de difícil enfrentamento. Em primeiro lugar, há uma dificuldade em explicar como objetos mentais podem interagir com objetos físicos, se assemelhar a eles, e corresponder a eles de alguma forma. Em segundo lugar, como podemos ter conhecimento da realidade física se não podemos jamais ir além do nosso "véu das representações” para checar se há objetos físicos que correspondam a elas? Assim, a persistência de problemas céticos - dentre os quais os mais destacados são o "problema do mundo exterior" e o "problema das outras mentes" - estimulavam os filósofos a desenvolverem explicações alternativas sobre o mental. ${ }^{1}$

1 É digno de nota que Sellars move o seu próprio ataque à tradição cartesiana nas oito primeiras parteds do seu ensaio. Ali ele argumenta contra a primazia epistêmica dos fatos mentais sobre os fatos acerca da realidade material, e contra o caráter fundacional das crenças do sujeito em relação aos 
Na metade do século XX, o principal contraponto ao cartesianismo em filosofia da mente era o chamado behaviorismo lógico. Segundo o behaviorismo lógico, um estado mental qualquer de um sujeito deve ser reduzido sem resíduo a um complexo de comportamentos e disposições de comportamentos em certas circunstâncias. Por exemplo, "S tem dor de dente" seria definido em termos de "Se S está nas circunstâncias C, então S realiza tais e tais movimentos"; e "S pensa que $p$ " seria definido em termos de “Se S está nas circunstâncias C, então S realiza tais e tais movimentos e profere 'p"”. O behaviorismo lógico prometia integrar o fenômeno mental ao mundo natural - público e intersubjetivo - e assim evitar o surgimento de problemas céticos, que eram a fraqueza do cartesianismo.

No entanto, o projeto behaviorista também apresentava graves dificuldades. Em primeiro lugar, enquanto o behaviorismo conseguia explicar bem o nosso conhecimento a respeito dos estados mentais das outras pessoas, ele tinha muita dificuldade em explicar o conhecimento dos nossos próprios estados mentais. ${ }^{2}$ Em segundo lugar, e ainda pior, o objetivo do behaviorismo lógico mostrou-se inalcançável: era uma tarefa extremamente difícil definir conceitos psicológicos em função de conceitos físicos e comportamentais. As traduções do mental em termos do não-mental eram ou grosseiras demais ou disfarçadamente circulares (ou seja, incluindo termos mentais no definiens, como em "S acredita que $p$ " = "Se alguém perguntar tal e tal coisa a S, e S desejar falar a verdade, S profere 'p"”).

Vale a pena ainda fazer uma observação que abrange ambas as posições. Pensamentos envolvem atitudes proposicionais por parte do sujeito - crer, desejar, duvidar etc.; sensações envolvem um sujeito estando consciente dos objetos imediatos da sua experiência - ter uma impressão de cor, de forma, dor, alegria, etc. De acordo com Sellars, a tradição cartesiana havia assimilado o conceito de sensação ao conceito de pensamento, tratando o primeiro como uma espécie deste último e explicando a

seus próprios estados mentais na arquitetura do conhecimento. O nosso suposto conhecimento infalível e fundacional dos objetos da experiência imediata não passaria de uma instância do chamado "mito do Dado".

2 O behaviorista lógico tinha duas opções, ambas absolutamente insatisfatórias: (i) sustentar que o conhecimento a respeito dos nossos próprios estados mentais se fundamenta na observação dos próprios comportamentos; ou (ii) negar que os usos de conceitos mentais em primeira pessoa tenham qualquer função epistêmica para nós mesmos, isto é, negar que nós realmente saibamos dos nossos próprios estados mentais - como fazem Ryle e o segundo Wittgenstein. 
diferença entre eles como sendo apenas uma diferença de complexidade e especificidade (EFM, §25). Os behavioristas lógicos, por sua vez, herdaram passivamente o tratamento mais ou menos unificado dado aos pensamentos e sensações. Sellars, no entanto, sustentava que essa assimilação era profundamente equivocada. A diferença entre pensamentos e sensações deveria ser considerada uma diferença de tipo, de modo que a ela deveria corresponder, no nível da linguagem, uma diferença na gramática das expressões que pertencem às categorias de pensamento e sensação.

A filosofia da mente de Sellars mantém uma relação complexa com a tradição filosófica. Enquanto Sellars atribuía falhas graves tanto ao cartesianismo quanto ao behaviorismo lógico, ele pensava que ambas as propostas tinham virtudes que deveriam preservadas na sua própria proposta alternativa. Do cartesianismo, Sellars pretendia reter a intuição de que nós temos um acesso privilegiado aos nossos próprios estados mentais; do behaviorismo lógico, Sellars pretendia manter a ideia de que os termos psicológicos pertencem à linguagem pública, e que, portanto, os falantes de uma determinada língua o compreendem da mesma maneira. Por fim, distanciando-se de ambas as vertentes e aproximando-se da tradição kantiana, Sellars postulava uma diferença de natureza entre pensamentos e sensações - limitando a categoria dos pensamentos àqueles estados mentais que envolvem atitudes proposicionais por parte do sujeito.

\section{O "MITO" RYLIANO}

Em EFM, Sellars apresenta a sua própria filosofia da mente através de um experimento mental, ou, segundo o autor, uma “ficção científica antropológica” (EFM, §48). Sellars nos fala de uma comunidade ancestral fictícia, situada em algum ponto remoto da nossa história, que possuía uma linguagem espécie de protolinguagem. Tal sistema de comunicação era sofisticado o suficiente para permitir que os membros daquela comunidade falassem sobre o ambiente ao seu redor, mas não sobre os seus próprios estados mentais. Sellars narra então a saga desses ancestrais ficcionais rumo à “descoberta” do fenômeno mental e a “invenção” de expressões linguísticas capazes de descrevê-lo adequadamente.

Através do chamado “mito ryliano”, Sellars buscava mostrar a plausibilidade da seguinte tese: as duas categorias básicas do discurso psicológico são pensamentos e sen- 
sações; e elas são logicamente posteriores a categorias próprias da linguagem pública e intersubjetiva. ${ }^{3}$ No que tange especificamente ao tema do trabalho, o ponto de Sellars é propor que alguém só compreende o conceito de pensamento (e as suas espécies, como crença, desejo, dúvida) se já domina (i) os conceitos adequados para descrever a realidade física, bem como seu aparato lógico; (ii) os conceitos e aparatos lógicos adequados para se falar dos conceitos de primeira ordem inclusos em (i) - ou seja, conceitos metalinguísticos; e (iii) a habilidade de criar teorias para explicação dos fenômenos. Note-se que, enquanto Sellars pretende reservar aos comportamentos verbal e não verbal um papel essencial na gramática dos pensamentos, ele não define pensamentos em termos de comportamento (e disposições de comportamento). Este é o ponto onde Sellars se afasta definitivamente do behaviorismo lógico.

Analisamos aqui o experimento em cinco “etapas”, de modo que a cada etapa posterior ao ponto de partida representa um encurtamento da distância entre a linguagem dos rylianos e o nosso discurso sobre pensamentos, tal como ocorre nas nossas linguagens naturais.

\subsection{ETAPA 1}

No ponto de partida, os membros da comunidade ancestral fictícia dispõem de um sistema de comunicação com as seguintes características (EFM, §48):

(1) um léxico e uma sintaxe que permitissem aos sujeitos falarem de objetos físicos e eventos no espaço-tempo;

(2) operadores lógicos e quantificadores;

(3) vagueza e "textura aberta" 4

3 Devemos entender que um conceito A é logicamente posterior a B (ou B anterior a A) quando, dado um sujeito S, S é capaz de compreender A apenas se S já é capaz de compreender B. Assim, dizemos, por exemplo, que o conceito de aceleração é logicamente posterior ao conceito de velocidade, porque ninguém pode compreender o conceito de aceleração sem compreender o conceito de velocidade (embora o contrário seja possível).

4 De acordo com DeVries \& Triplett (2000: p. 127n2), a vagueza e a "textura aberta" vão além da imprecisão de limite conceitual. Elas permitem também a existência de "relações lógicas frouxas" entre expressões linguísticas, como em "Cães tem quatro patas" (evidentemente, nas linguagens naturais, essa frase quer dizer que cães tem paradigmaticamente quatro patas, e não que literalmente todos os cães tem quatro patas) e ainda a expressão de probabilidades ("Se A ocorre, então provavelmente B ocorre”). 
Tal sistema é chamado de "linguagem ryliana" porque, de acordo com a teoria de Gilbert Ryle, seus recursos linguísticos já seriam suficientes para obtermos uma definição para todos os nossos conceitos psicológicos.

Notemos que Sellars inclui explicitamente entre os elementos lógicos desse sistema os chamados “condicionais subjuntivos" (“Se fosse o caso que A, então B ocorreria”), que permitem expressar necessidades naturais. Esse ponto é de especial importância, porque dá aos nossos ancestrais ficcionais o vocabulário disposicional que o behaviorista lógico precisa para realizar a sua proposta. Assim, os rylianos estão aptos a descreverem o fenômeno comportamental com a mesma precisão e eficiência que nós (“Se João atingisse seu próprio dedo com um martelo, ele diria “Ai!”).

Agora, enquanto crítico do behaviorismo Sellars sustenta que os recursos da "linguagem” ryliana ainda não permitem que os nossos ancestrais fictícios possam descrever adequadamente - isto é, como nós descrevemos - os fenômenos mentais. O ponto então é: quais recursos precisam ser adicionados a essa "linguagem" a fim de obtermos nossos conceitos psicológicos - em especial o conceito de pensamento? Por quê? A resposta a essas questões nos leva às próximas duas etapas do experimento.

\subsection{ETAPA 2}

O primeiro acréscimo a ser feito, de acordo com Sellars, diz respeito ao discurso semântico. Os recursos do discurso semântico possibilitariam aos nossos ancestrais ficcionais falar sobre a "linguagem" ryliana da etapa 1, isto é, daria a eles o poder de formular enunciados metalinguísticos (ex: “ 'x' quer dizer/significa y”, “O enunciado 'p' é verdadeiro”, “A palavra 'x' se refere ao objeto...”) (EFM, §49).

Não é difícil perceber porque o discurso semântico é necessário para a realização do projeto behaviorista: a análise de muitos conceitos psicológicos pertencentes à categoria dos pensamentos deverá remeter a comportamentos verbais envolvendo o uso de metalinguagem. Por exemplo, a análise de "S compreende mal 'y" seria algo como "S se comporta como se ' $y$ ' quisesse dizer $x$, e 'y' quer dizer y”. Além disso - e este ponto interessa profundamente a Sellars - é um traço característico dos pensamentos que a eles se apliquem propriedades semânticas (ex: "A crença de S de que é verdadeira", “O pensamento de S se refere ao objeto $a$ ”) O mais complicado, então, é 
entender porque, na opinião de Sellars, o discurso semântico deve ser acrescentado à linguagem ryliana, ao invés de ser derivado a partir dela.

O behaviorista lógico poderia vir a sustentar que o discurso semântico, tal qual o discurso psicológico, já está implicitamente incluído na linguagem da etapa 1. Ele poderia oferecer uma teoria behaviorista da linguagem, definindo o significado das expressões linguísticas em termos de correlações causais entre estímulos ambientais recebidos por um indivíduo (input) e comportamentos verbais (output). Seguindo essa lógica, poderíamos, por exemplo, definir a propriedade de ser "bleh" ou "blehidade" como a característica presente em objetos nas proximidades dos sujeitos no momento em que proferem “Bleh agora!”, “Isto é bleh! etc, e ausente quando os sujeitos não estão inclinados a fazer tais proferimentos. Por conseguinte, “S utilizar 'bleh' corretamente" acaba por ser igualado com "S ser um indicador confiável da presença de coisas que são bleh"; não por acaso Sellars chama essa concepção do significado de "visão termômetro" (EFM, §31).

Agora, Sellars rejeitaria em absoluto essa proposta, não importando o quanto essa imagem inicialmente tosca pudesse ser melhorada para ganhar plausibilidade. Nas palavras do próprio autor:

(...) fazer um enunciado semântico sobre eventos verbais não é uma forma abreviada de falar sobre suas causas e efeitos, mesmo que haja um sentido de "implicar" segundo o qual enunciados semânticos sobre produções verbais $i m$ plicam informação sobre causas e efeitos dessas produções. Logo, quando digo “'Es regnet' significa está chovendo", meu enunciado "implica” que as causas e efeitos de enunciados de "Es regnet" além do Reno equivalem às causas e efeitos de enunciações de "Está chovendo" minhas e de outros membros da comunidade de falantes da língua portuguesa. E se não implicasse isso, não poderia executar seu papel. Porém, com isso não queremos dizer que enunciados semânticos sejam abreviações definicionais de enunciados acerca de causas e efeitos de performances verbais. (EFM, §49)

Esta atitude de Sellars se justifica tendo em vista por um lado a sua filosofia da linguagem, e por outro as suas posições mais gerais em filosofia. Sellars compreendia a linguagem como uma prática governada por regras, e sustentava que o seu caráter normativo intrínseco não pode ser reduzido sem resíduo a qualquer outra coisa não normativa. Em outras palavras, Sellars pensava que o discurso semântico - enquanto 
contendo termos normativos - não pode ser satisfatoriamente explicado utilizando-se um discurso que dispensasse por completo esses termos. A análise correta de enunciados da forma “' $\mathrm{x}$ ' (na linguagem $\mathrm{L}$ ) significa $\mathrm{y}$ " inclui, como foi indicado na citação acima, enunciados envolvendo disposições dos sujeitos; mas, além disso, e principalmente (tal coisa está ausente na citação acima e no próprio EFM), deverá incluir enunciados a respeito do que os sujeitos que usam um termo de uma determinada linguagem estão autorizados, proibidos e obrigados a dizer e fazer em tais e tais circunstâncias. ${ }^{5}$

Essa tese da irredutibilidade do normativo ao não normativo é forte e não trivial, e uma exposição satisfatória dos argumentos em seu favor seria complexa demais para os propósitos e o tamanho deste trabalho. No entanto, cumpre ressaltar que essa tese - implícita no contexto do EFM - parece ser um primeiro e importante movimento de Sellars para se afastar do behaviorismo lógico e das tendências reducionistas dessa tradição.

Os recursos disponíveis na etapa 2 ainda não são adequadamente suficientes para se derivar o conceito de pensamento, pois, contando apenas com os recursos disponíveis ali, seria possível desenvolver apenas uma variante do behaviorismo lógico; uma versão que, do ponto de vista de Sellars, tivesse como fundamento uma compreensão correta sobre linguagem e significado. Sellars, no entanto, pretende oferecer uma teoria que correlacione estados mentais com comportamentos sem analisar os primeiros em função destes últimos. Apenas evitando isso, pensa Sellars, ele é capaz de escapar das dificuldades do behaviorista em explicar satisfatoriamente e de modo não circular, como pensamentos e comportamentos estão intrinsecamente relacionados.

5 DeVries (2005: p.191) destaca que Sellars, em trabalhos posteriores a EFM, faz uma distinção entre sistema de representação e linguagem. Aquilo que muitos cientistas chamam de "linguagem", quando falam dos sistemas de signos utilizados por animais para se comunicarem, seria então classificado como um sistema de representação. Uma linguagem propriamente dita seria um sistema de comunicação que permite aos seus usuários fazer referência ao próprio sistema - e isto envolve exatamente os elementos do discurso semântico. Assim, o que os rylianos possuem na etapa 1 é, de acordo com os critérios de Sellars, um sistema de representação altamente complexo - verdadeiramente uma protolinguagem, mas não ainda uma linguagem. 


\subsection{ETAPA 3}

Nesta etapa uma importante ferramenta metodológica é atribuída aos rylianos, que é a capacidade de fazer teorizações. No nível da linguagem, isso corresponde à introdução da distinção entre discurso observacional e discurso teórico.

O vocabulário observacional consiste naqueles termos os quais nós podemos aplicar diretamente aos objetos e eventos, em proferimentos que desempenham o papel de relato. Ter um papel de relato significa não ser produto de inferências realizadas pelo sujeito, mas, pelo contrário, ser uma espécie de comportamento verbal básico associado à percepção de um objeto, propriedade ou ocorrência de um evento. ${ }^{6}$ De modo geral, os termos que nós utilizamos para a simples descrição de estados de coisas envolvendo objetos físicos cotidianos são termos observacionais. No que se refere a nosso experimento mental, podemos admitir que todo o vocabulário fisicalista inicial dos rylianos é observacional.

O vocabulário teórico, por sua vez, se constitui de termos que denotam objetos, propriedades e eventos que não são diretamente observáveis por nós, mas cuja postulação envolve um ganho explicativo com respeito aos fenômenos observáveis. Por exemplo, ao postular a existência da força gravitacional, conseguimos correlacionar fenômenos aparentemente muito diferentes e desconexos entre si, como a queda dos corpos, a variação das marés e as órbitas planetárias.

Resumidamente, Sellars concebe uma teoria como um conjunto de princípios fundamentais a respeito do comportamento de entidades não diretamente observáveis, correlacionado (e possivelmente identificado) com conjuntos de enunciados envolvendo termos observacionais. "Uma boa teoria 'explica' leis empíricas estabelecidas derivando contrapartes teóricas dessas leis a partir de um pequeno conjunto de postulados relativos a entidades não observáveis" (EFM, §51).

No que tange à relevância da teorização para o mito ryliano, Sellars faz duas observações essenciais. A primeira é que objetos (e eventos) teóricos são introduzidos em uma linguagem tendo um domínio de objetos e eventos observacionais como modelo.

6 Um enunciado não ser resultado de uma inferência não é o mesmo que não ser passível de justificação. Apesar de Sellars abrir espaço para o uso de relato de enunciados, ele ainda rejeita o fundacionalismo enquanto teoria da justificação epistêmica. 
Isso significa que as entidades teóricas, ao serem introduzidas, são caracterizadas como sendo semelhantes, em certos aspectos, a determinados objetos do discurso não teórico (EFM, §51) Teorias atômicas, por exemplo, são famosas por utilizarem modelos: Dalton comparou átomos a bolas de bilhar; Chadwick, a pudins de passas, e Niels Bohr a sistemas planetários. O ponto crucial para o mito é justamente que, na próxima etapa, episódios linguísticos serão utilizados como modelo para pensamentos.

A segunda observação é que as formas de raciocínio do senso comum são contínuas com os tipos de raciocínio postulacional que os cientistas empregam ao desenvolver teorias sobre objetos não observáveis que explicam o comportamento dos observáveis (EFM, §51). Por exemplo, podemos afirmar que mitologias são formas (pré-científicas) de exercício da capacidade de teorização, que utilizam seres humanos e animais como modelos para as divindades. Isso aponta para a plausibilidade de se atribuir a uma comunidade tão rudimentar como a dos rylianos a capacidade de teorizar. Com a etapa 3 obtemos uma linguagem que dispõe de todos os recursos necessários para o desenvolvimento do discurso psicológico - em especial o conceito de pensamento.

\subsection{ETAPA 4}

Sellars apresenta no início da parte XV a figura de Jones, uma espécie de gênio dos rylianos, destinado a realizar o progresso conceitual e inventar a linguagem psicológica. Em um determinado momento de sua vida, Jones se vê intrigado pelo fato de que, em várias situações, seus companheiros exibem comportamento inteligente sem a concomitância de comportamento verbal manifesto. Jones se vê então impelido a buscar uma explicação:

Suponha, agora, que na tentativa de explicar o fato de que seus companheiros se comportam de forma inteligente não somente quando sua conduta está tecida por uma cadeia de episódios verbais públicos - ou seja, como nós expressaríamos , quando eles "pensam em voz alta” -, porém também quando nenhum output verbal detectável está presente, Jones desenvolva uma teoria de acordo com a qual enunciados públicos são a culminação de um processo que começa com certos episódios internos. (EFM, §56)

Podemos imaginar aqui dois tipos de situação especialmente curiosas: (i) aprendizagem de tarefas complexas e (ii) processos de deliberação. O primeiro tipo de situação ocorre, por exemplo, quando Jones observa as intrincadas práticas de caça dos seus 
companheiros. Os mestres de caça passam seu conhecimento através de uma série de instruções, que envolve desde emboscar a presa até o uso correto das armas. Nas primeiras lições, os mestres de caça orientam os pequenos rylianos passo a passo. Com o tempo, os jovens passam a executar as tarefas com presteza sozinhos e em silêncio, e Jones nota que é como se eles estivessem ouvindo cada orientação dada pelos seus mestres. O segundo tipo ocorre quando pessoas decidem fazer algo ou chegam a uma conclusão e a expressam através de um proferimento. Jones imagina que nesses casos é como se o proferimento feito pela pessoa fosse na verdade a última de um conjunto de frases encadeadas em um raciocínio, e como se as outras frases tivessem sido proferidas internamente pela pessoa.

Jones postula então a existência de episódios internos aos sujeitos e que possuiriam forma linguística:

Suponhamos que seu modelo para esses episódios que iniciam os eventos que culminam em comportamento verbal público seja o do comportamento verbal público ele próprio. Em outras palavras, e usando a linguagem como do modelo, a teoria tem como resultado que o comportamento verbal público é a culminância de um processo que começa com a" fala interna”. (EFM, §56)

As características do modelo aplicáveis aos episódios internos postulados por Jones - que ele chama de pensamentos (EFM §58) - são fundamentalmente aquelas características expressas por predicados semânticos tais como "querer dizer”, "referir-se”, “ser verdadeiro", etc. Por outro lado, uma série de características próprias dos proferimentos são deixadas de lado: pensamentos não são concebidos por Jones como possuindo estrutura fonética, ocorrendo em uma determinada língua ou sendo compostos por palavras.

Este último ponto pode parecer estranho, porque frequentemente associamos a atividade de pensar com a ocorrência de imagens verbais internas. Notemos, entretanto, que os rylianos ainda não possuem o conceito de imagem interna (verbal ou de qualquer outro tipo); tal conceito só é desenvolvido numa etapa posterior do mito ryliano (parte XVI de EFM) - a qual não iremos cobrir aqui. Isso não quer dizer que os pensamentos - tanto os nossos como dos rylianos - não sejam frequentemente acompanhados de imagens internas, mas que tais imagens não fazem parte da gramática da categoria dos pensamentos. Pelo contrário, o experimento como um todo pretende 
mostrar que imagens internas constituem elas próprias uma categoria autônoma, a categoria das impressões. ${ }^{7}$

Outro ponto fundamental que deve ser esclarecido aqui é: em que sentido devemos entender os episódios postulados por Jones como sendo internos? De acordo com Sellars, no momento do surgimento da teoria, "interno" não significa nada mais que “teórico”, “não diretamente observável”. Tais episódios estão “dentro” de animais usuários de linguagem da mesma maneira que colisões entre moléculas estão "nos" gases (EFM, §58); isto é, episódios discursivos internos constituem (ou talvez constituam) animais usuários da linguagem assim como moléculas em constante colisão constituem gases. Com estas observações, Sellars deixa claro que Jones não está de início pressupondo nada parecido com uma substância imaterial da qual os pensamentos seriam "feitos".

A teoria de Jones é uma teoria inaugural, rudimentar e incompleta, deixando sem respostas as questões acerca da natureza mesma dos pensamentos e de como eles se relacionam com nossos organismos. A teoria permite que, posteriormente, os pensamentos sejam tanto identificados com uma substância imaterial quanto associados com estados neurofisiológicos; tanto o dualismo cartesiano quanto o fisicalismo se apresentam como desenvolvimentos possíveis - embora evidentemente incompatíveis - da teoria jonesiana. Lacunas explicativas não são fazem por si só com que uma teoria deixe de ser cientificamente respeitável - ainda mais no momento de sua criação: por exemplo, o mecanismo de transmissão de características entre gerações - elemento essencial da teoria da evolução de Darwin - só começou a ser elucidado no nível bioquímico nos anos 1950, com a descoberta da molécula de DNA.

\subsection{ETAPA 5}

Depois de desenvolver a sua teoria, Jones ensina os seus companheiros a interpretar os comportamentos uns dos outros como evidência para a ocorrência de determinados pensamentos: "Se S se comporta de tal e tal modo nas circunstâncias C... então,

7 Se os rylianos ainda não possuem o conceito de imagem interna, então como eles experienciam as imagens internas que costumam acompanhar os seus pensamentos? DeVries \& Triplett (2000, pp.144-145) sugerem que os rylianos simplesmente não as experienciam como sendo internas. Eles experienciariam essas imagens internas como sendo objetos reais, tal como alguém que esteja sonhando experiencia o sonho como sendo real. 
(provavelmente) S pensa que p". Nesse primeiro momento, mesmo as autoatribuições de pensamento feitas pelos rylianos são fundamentadas em observações do próprio comportamento:

(...) quando Tom, observando Dick, tem evidência comportamental que sustenta o uso da frase (na linguagem da teoria) "Dick está pensando 'p”" (...), Dick, usando a mesma evidência comportamental, pode dizer, na linguagem da teoria, “Eu estou pensando 'p"”(...) (EFM, §59)

Com o passar do tempo, entretanto, os rylianos passam a utilizar enunciados de pensamento em $1^{\text {a }}$ pessoa com a função de relato:

(...) Dick pode ser treinado a dar autodescrições razoavelmente confiáveis usando a linguagem da teoria, sem ter de observar seu comportamento público. Jones consegue isso, de forma aproximada, aplaudindo enunciações de Dick de "Eu estou pensando que p" quando evidência comportamental apoia fortemente o enunciado teórico "Dick está pensando que p"; e desaprovando enunciações de "Eu estou pensando que p", quando a evidência não apoia esse enunciado teórico. Nossos ancestrais começam a falar do acesso privilegiado que cada um de nós tem a seus próprios pensamentos. (EFM, §59)

Assim, os rylianos alcançam um ponto da história a partir do qual eles passam a usar expressões características do discurso dos pensamentos de maneira semelhante a nós, ou seja, como nós as utilizamos nas linguagens naturais.

O que dizer sobre essa transição uso teórico/uso observacional? De acordo com o modo de pensar sellarsiano, tais transições realmente acontecem na realidade - embora não no caso do discurso sobre pensamentos. ${ }^{8}$ Evidentemente, não supomos (e nem Sellars estava supondo) que primeiro nós aprendemos a fazer autoatribuições de pensamento de maneira inferencial, isto é - como resultado de inferências a partir da percepção de nosso próprio comportamento - para somente depois aprendermos a fazer tais proferimentos como relatos. Mas, de fato, supomos que nós fazemos um

8 A distinção teórico/observacional é, além de vaga, móvel. Conceitos que são apresentados a alguém dentro de uma teoria podem vir a ser usados por essas pessoas de um modo "direto", não inferencial. Por exemplo, enquanto a detecção de um câncer de pulmão por um estudante de radiologia deverá envolver uma série de inferências a partir da imagem de raio-X, um radiologista experiente conseguirá ver o tumor “diretamente” na chapa. No caso deste último, os aspectos próprios da radiografia que fundamentam o diagnóstico ainda são notados, mas não explicitamente. Eles foram sublimados para abaixo do nível da consciência. 
uso de relato em $1^{\text {a }}$ pessoa (e a nossa inclinação é supor que fazemos isso desde o momento em que aprendemos a fazer autoatribuições de pensamento), e que, de fato, nós temos um acesso aos nossos próprios pensamentos que é de algum modo privilegiado. E, a respeito de como chegamos a ter esse acesso direto aos nossos pensamentos via introspecção, a história de Sellars nos deixa com um mistério.

Em defesa de Sellars, DeVries \& Triplett sustentam que ele não poderia - enquanto filósofo - oferecer uma explicação clara dos mecanismos por meio dos quais essa habilidade é adquirida e exercitada. Eles pressupõem que, por dizer respeito a uma questão empírica, esta deveria ser tratada pelas ciências naturais - especificamente a psicologia. 9

Entretanto, embora este seja um bom ponto feito pelos comentadores, eu penso que Sellars ainda precisaria apresentar as linhas gerais do que contaria como sendo uma explicação científica neste caso particular. De que forma uma teoria científica conseguiria explicar que relatos baseados na introspecção são mais confiáveis que aqueles, feitos por terceiros, baseados na percepção do comportamento? Como relatos baseados na introspecção (e não da percepção) são epistemicamente justificados? Embora não seja tarefa do filósofo apresentar explicações científicas sobre os fatos, é ainda sua tarefa dizer como as explicações científicas podem ser relevantes para a filosofia.

\section{OBSERVAÇÕES FINAIS}

Sellars teria apresentado, com o seu mito, uma filosofia da mente que consegue evitar os vícios do cartesianismo e do behaviorismo lógico, ao mesmo tempo preservando as suas virtudes. O que se extrai do mito é que a posse do conceito de pensamento - incluindo seus usos com papel de relato em $1^{\mathrm{a}}$ pessoa - pressupõe a posse de uma série de habilidades associadas ao domínio da linguagem pública, intersubjetiva. No entanto, o experimento mental de Sellars não deve ser entendido como uma demonstração inescapável dessa tese. A meu ver, o mito é mais bem compreendido como afirmando que o discurso psicológico - e em particular o discurso sobre pensamentos - pode ser plausivelmente interpretado como derivado de discursos da linguagem pública. Agora, ainda que o mito não seja uma demonstração dessa tese, ele é ao menos uma defesa des-

9 DeVRIES, Willem. \& TRIPLETT, Tim. Knowledge, Mind and the Given. p. 154. 
sa tese. Ao construir uma história verossímil que mostrasse a sua tese como sendo verdadeira, Sellars pretendia ao menos ter a melhor concepção do mental disponível no “mercado filosófico" - pelo simples fato de ser menos problemática que as suas rivais.

É a teoria de Sellars mais plausível, mais atrativa, que as linhas de pensamento adversárias? Embora eu não pretenda responder essa questão aqui, cabe ao menos fazer algumas observações a respeito do que pode tornar a teoria de Sellars menos ou mais plausível, apontando dificuldades e possíveis caminhos para superá-las.

Em primeiro lugar, Sellars considerava que a filosofia possui uma natureza holística, de modo que, para se tratar adequadamente de um tema particular, é necessário tratar adequadamente muitos outros temas que estão ligados a ele. A atratividade de sua filosofia da mente depende em particular da atratividade de sua filosofia da linguagem, de sua filosofia da ciência, e, ainda, de uma tese forte que perpassa todo o seu pensamento, a saber, a tese da irredutibilidade de aspectos normativos a aspectos puramente factuais. ${ }^{10}$

Em segundo lugar, a teoria de Sellars não depende, de maneira alguma, que a história real das linguagens humanas se assemelhe a história dos rylianos. O ponto que Sellars procura fazer com o seu mito é puramente conceitual. Do ponto de vista empírico, é provável que o discurso metalinguístico, a capacidade de teorizar e o discurso psicológico tenham surgido concomitantemente, nos primórdios da civilização. E é também provável que nós, individualmente, venhamos a aprender a usar os conceitos de pensamento de forma paulatina e concomitante com os conceitos fisicalistas e metalinguísticos. Sellars precisa apenas que sua história seja concebível, possível; que alguém possa ter os recursos da linguagem pública - em especial, os recursos do discurso semântico - sem ter os conceitos de pensamento, mas que o contrário não seja possível.

10 Estes pontos voltam a ganhar destaque quando Sellars vem a fazer considerações sobre as consequências do próprio experimento - no que tange ao conceito de pensamento. De acordo com Sellars, no momento do seu surgimento o conceito de pensamento é como um conceito teórico, e não propriamente um conceito teórico (EFM, \$59). Triplett \& DeVries oferecem um comentário esclarecedor: "Nossos conceitos de estado mental (i. e., de pensamento) diferem dos conceitos teóricos precisamente na medida em que nossos conceitos de estado mental não são abandonáveis na forma em que conceitos puramente teóricos são. Pois Sellars pode argumentar que conceitos teóricos são desenvolvidos e empregados dentro da ciência - uma atividade de revisão conceito/linguagem estruturada de acordo com normas bem explícitas e realizadas por seres racionais. Mas os conceitos de mentalidade não são nem desenvolvidos no contexto de uma investigação científica explícita (...) nem poderiam eles ser razoavelmente abandonados no contexto das contínuas descobertas científicas.” (2000, p. 135). 
Além disso, é importante constatar dois pontos problemáticos na teoria da mente que Sellars apresenta em EFM. O primeiro ponto foi apresentado no fim da última seção: há uma relação entre o uso em $1^{\text {a }}$ pessoa com caráter de relato que fazemos de termos de pensamento, e com base na introspecção, com o uso em $3^{\text {a }}$ pessoa desses mesmos termos, baseado em evidências comportamentais intersubjetivamente acessíveis. Além disso, embora os usos em $1^{\mathrm{a}}$ pessoa sejam mais confiáveis que os usos em $3^{\mathrm{a}}$ pessoa, a força epistêmica do uso de relato, baseado na introspecção, é derivada da força epistêmica de usos em $3^{\text {a }}$ pessoa, baseado na percepção de comportamentos. Pode-se dizer que uma explicação detalhada dos mecanismos envolvidos na introspecção deve ser dada pelo cientista; mas, como destacamos, no EFM Sellars fica nos devendo até mesmo um esclarecimento de como uma investigação científica poderia ser útil ao filósofo nesse ponto em particular.

O segundo ponto é que, pelas colocações de Sellars no EFM fica subentendido, ou ao menos sugerido, que a habilidade de ter pensamentos é intrinsecamente dependente da habilidade de utilizar uma linguagem. Se isto é assim, então surge a dificuldade de explicar nossas atribuições de pensamentos a seres inteligentes infralinguísticos, como animais e bebês. Embora bebês, cães e macacos não utilizem aquilo que Sellars chama de linguagem, é inegável que eles exibem comportamento inteligente, e que temos bons motivos para atribuir a eles pensamentos de baixo grau de complexidade (que eles desejam certo tipo de comida, por exemplo).

Para a sorte de Sellars, essas duas dificuldades tem mais o caráter de lacuna explicativa, que pode vir a ser satisfatoriamente preenchida - do que de vício irrecuperável. Nesse sentido, o próprio Sellars, possivelmente ciente dessas lacunas, veio a complementar e revisar as posições apresentadas no EFM em trabalhos posteriores. A discussão da relação entre os usos em $1^{\mathrm{a}}$ e $3^{\mathrm{a}}$ pessoa de termos de pensamento é retomada em seu artigo The Structure of Knowledge II: Minds; e a discussão sobre a atribuição de pensamentos a animais infralinguísticos é feita em seu artigo Mental Events. 


\section{BIBLIOGRAFIA}

DeVRIES, Willem. Wilfrid Sellars Chesham: Acumen, 2005.

DeVRIES, Willem \& TRIPLETT, Tim. Knowledge, Mind and the Given. Indianápolis: Hackett Publishing Company, 2000.

KIM, Jaegwon. Philosophy of Mind. Boulder, Colorado: Westview Press, 1998.

SELLARS, Wilfrid. Empirismo e Filosofia da Mente. Tradução: Sofia Inês Albornoz Stein. Petrópolis: Vozes, 2008. 